\title{
Crystalline silicon cell performance at low light intensities
}

\author{
N.H. Reich ${ }^{\text {a,* }}$, W.G.J.H.M. van Sark ${ }^{\text {a }}$, E.A. Alsema ${ }^{a}$, R.W. Lof ${ }^{c}$, R.E.I. Schropp ${ }^{c}$, W.C. Sinke ${ }^{\text {, }}$ \\ W.C. Turkenburg ${ }^{a}$ \\ ${ }^{a}$ Utrecht University, Faculty of Science, Copernicus Institute for Sustainable Development and Innovation, Department of Science, Techonology and Society, \\ Heidelberglaan 2, 3584 CS Utrecht, The Netherlands \\ ${ }^{\mathrm{b}}$ Energy research Centre of the Netherlands (ECN), P.O. Box 1, 1755 ZG Petten, The Netherlands \\ ${ }^{\mathrm{c}}$ Utrecht University, Faculty of Science, Debye Institute for Nanomaterials Science, Nanophotonics_Physics of Device, Utrecht University, P.O. Box 80.000, \\ 3508 TA Utrecht, The Netherlands
}

\section{A R T I C L E I N F O}

\section{Article history:}

Received 4 February 2009

Accepted 19 March 2009

Available online 9 May 2009

\section{Keywords:}

Solar cell efficiencies

STC

PV energy yields

Energy rating

Weak light performance

Product Integrated PV (PIPV)

\begin{abstract}
A B S T R A C T
Measured and modelled $J V$ characteristics of crystalline silicon cells below one sun intensity have been investigated. First, the $J V$ characteristics were measured between 3 and $1000 \mathrm{~W} / \mathrm{m}^{2}$ at 6 light levels for 41 industrially produced mono- and multi-crystalline cells from 8 manufacturers, and at 29 intensity levels for a single multi-crystalline silicon between 0.01 and $1000 \mathrm{~W} / \mathrm{m}^{2}$. Based on this experimental data, the accuracy of the following four modelling approaches was evaluated: (1) empirical fill factor expressions, (2) a purely empirical function, (3) the one-diode model and (4) the two-diode model. Results show that the fill factor expressions and the empirical function fail at low light intensities, but a new empirical equation that gives accurate fits could be derived. The accuracy of both diode models are very high. However, the accuracy depends considerably on the used diode model parameter sets. While comparing different methods to determine diode model parameter sets, the two-diode model is found to be preferred in principle: particularly its capability in accurately modelling $V_{O C}$ and efficiency with one and the same parameter set makes the two-diode model superior. The simulated energy yields of the 41 commercial cells as a function of irradiance intensity suggest unbiased shunt resistances larger than about $10 \mathrm{k} \Omega \mathrm{cm}^{2}$ may help to avoid low energy yields of cells used under predominantly low light intensities. Such cells with diode currents not larger than about $10^{-9} \mathrm{~A} / \mathrm{cm}^{2}$ are excellent candidates for Product Integrated PV (PIPV) appliances.
\end{abstract}

(c) 2009 Elsevier B.V. All rights reserved.

\section{Introduction}

In our research towards improved methods and tools to design and Product Integrated PV (PIPV) [1], it was found that industrial product designers frequently encounter problems regarding solar energy harvesting predictions. As PIPV systems are likely to be operated close to their owners, this is most often indoors rather than outdoors. Therefore, light intensities are much lower, and further the spectral composition of solar radiation can differ substantially compared to outdoor conditions, which is due to window glazing coatings. The temperature-related decrease of solar cell performance, on the other hand, will only play a minor role, simply because at low light intensities only limited warming of cells occurs. Spectral and irradiance intensity effects and the avoidance of temperature-related effects are very much in contrast to outdoor-operated PV systems; however, this can have

\footnotetext{
* Corresponding author.

E-mail address: n.h.reich@uu.nl (N.H. Reich).
}

a substantial impact on the operational performance of PIPV solar cells.

To investigate the challenges of PIPV product design, we embarked upon a case study: the design and realization of the "SoleMio" PV powered wireless computer mouse. Various aspects of this research programme have already been described elsewhere, such as industrial design concepts [2], energy balance estimation tools [3,4], test-user experiences [6] as well as green product design [7] and environmental aspects [8] of the product involved.

To predict energy balances of PIPV more accurately, particularly the development of Computer Aided Design (CAD) based simulation tools [4,5] has been identified as a promising approach: Nowadays products are virtually created before manufacture. The routine use of CAD software is therefore standard for product designers. Consequently, incorporating PV performance models into CAD software would enable industrial designers to instantly evaluate the energetic performance of the product throughout the ongoing design process. For this, however, models that accurately predict the efficiency as a function of irradiance intensity are a necessity. In addition, 
accurate irradiation scenarios are of course required, but these are almost always application specific. Moreover, powerful CADembedded ray-tracing features offer the option to simulate application-specific irradiance scenarios. To this end, the focus of this article is on selecting modelling approaches and evaluating the accuracy of modelling methods that determine crystalline silicon cell performance as a function of light intensity.

Although several authors have investigated solar cell efficiency as a function of irradiance intensity below one sun intensity, most of these studies focus on the operational performance of gridconnected PV systems [9-27] or stand-alone PV systems [28] operated outdoors. Consequently, the focus is on outdoor irradiance conditions and solar cell efficiency only above $100 \mathrm{~W} /$ $\mathrm{m}^{2}$ is investigated. Grunow et al. [22] discussed the relationship between shunt resistance of industrial silicon-based solar cells and their energy yield. They were the first to calculate annually averaged efficiencies or effective efficiencies of commercially produced cells, in particular with respect to different classes of irradiance levels. An irradiance-level-classification approach was originally devised to characterize average inverter efficiencies under typical field conditions. ${ }^{1}$ A variation of $4 \%$ in energy yield of a grid connected, roof-top (outdoor) PV system was determined, based on only different shunt resistance classes of the solar cells used. Irradiance intensity distributions were also used by Burgers [29] to optimize the front side metallization pattern, which finally led to the well-known metallization pattern of the PUM cell [30]. Further, Topič et al. [27] investigated yield ranges of solar modules based on diode model parameters, to account for actual field conditions rather than only comparing STC-based efficiencies. In the case of building-integrated photovoltaic systems (BIPV), PV modules can be mounted such that they are sub-optimally orientated or shadowed to a large extent. The impact of thereby lowered irradiance intensities on PV performance was investigated by, e.g. Stamenic et al. [23] and Reinders et al. [31]. However, these studies, to name but a few, consider irradiance intensities of $100-1000 \mathrm{~W} / \mathrm{m}^{2}$ only, whereas energy yield predictions of PIPV systems also require solar cell performance models for intensities (far) below $100 \mathrm{~W} / \mathrm{m}^{2}$.

In the context of PIPV systems, relatively few solar cell performance studies have been conducted. Randall et al. [17-19] presented measured low light efficiencies of (laboratory) solar cells and an empirical model for cell performance, covering irradiance intensity levels between 1 and $1000 \mathrm{~W} / \mathrm{m}^{2}$. However, the tested cell samples were selected with regard to cell dimensions and not with respect to their technological availability or economic feasibility for integration into PIPV. Furthermore, it is not possible to apply their findings to commercially available solar cells, as relationships between measured low light performances and typical solar cell data was not presented. Gemmer and Schubert [16] studied low light performance of crystalline silicon (c-Si), amorphous silicon (a-Si) as well as $\mathrm{Cu}(\mathrm{In}, \mathrm{Ga}) \mathrm{Se}_{2}$ (CIGS) cells using the numerical computer model ASA [32] and the one-diode model. Although several improvements to the design of PIPV systems were suggested, the investigated model relies on typical cell characteristics (i.e., typical ranges of the typical parameters) in their study. Therefore, an energy yield prediction of the specific industrially produced cell that is to be integrated into a PV powered product is not yet possible. Finally, Merten et al. introduced [33] the Variable Illumination Method (VIM) to determine physical device properties by measuring cell characteristics over a broad range of irradiance intensities. The use of the

\footnotetext{
${ }^{1}$ Average inverter efficiencies result from weighting electricity throughput at irradiance intensity classes with inverter efficiency; also known as European efficiencies.
}

VIM method was demonstrated for energy rating purposes [12] and its usefulness to reveal four key performance parameters of PV modules was presented [34]. The principle idea of the VIM method, however, is to extract physical device performance parameters from measurements at various irradiance intensities rather than predicting irradiance intensity-dependent performances. Obviously, the IV characteristics of each candidate cell to be used in PIPV appliances could be measured over the whole irradiation range $1-1000 \mathrm{~W} / \mathrm{m}^{2}$, but this would be quite cumbersome. To this end, our study aims to tackle PV performance modelling such that electrical output characteristics below one sun intensity are predicted using only a limited number of input parameters and $J V$ curve measurements.

The structure of this paper is as follows: in Section 2 the experimental measurements are presented. In Section 3, four approaches to model solar cell performance as a function of irradiance intensity are described, encompassing: (1) fill factor expressions, (2) a purely empirical function, (3) the one-diode model and (4) the two-diode model. Results that highlight modelled characteristics compared to measured $J V$ characteristics are presented in Section 4, followed by a brief discussion in Section 5. Conclusions are drawn in Section 6.

\section{Experimental}

The current density/voltage (JV) curves at irradiance intensities between 3 and $1000 \mathrm{~W} / \mathrm{m}^{2}$ of three to ten crystalline silicon samples from eight manufacturers were measured using a SPECTROLAB solar simulator at the Energy research Centre of the Netherlands (ECN) [24]. In total, 41 commercially produced cells were measured. The various multi-crystalline silicon (mc-Si) and mono-crystalline silicon (c-Si) cell sample manufacturer codes, the overall number of samples from each supplier and the corresponding solar cell areas are listed in Table 1 . The desired irradiance intensity levels were attained placing neutral density filters into the light path of the solar simulator. Due to limited availability of filters larger than cell areas, however, the $J V$ curves of the 41 cells could only be measured at 6 different irradiance intensity levels. Therefore, we also measured the $J V$ curves of a $5 \mathrm{~cm}^{2}$ multi-crystalline silicon solar cell (denoted mc-Si cell) using a calibrated dual-source WACOM solar simulator at Utrecht University (UU). In this case, available neutral density filters allowed us to measure $J V$ curves at as many as 29 different light intensity levels ranging from 0.04 to $1000 \mathrm{~W} / \mathrm{m}^{2}$.

\subsection{Measurement procedure and error estimation}

The spectra and temperature have been kept as defined in STC (air mass (AM) 1.5 and temperature of $25^{\circ} \mathrm{C}$ ). Hence, only the irradiance intensity level differs from STC. Due to the use of filters, however, some additional inhomogeneity and a change in spectral

\section{Table 1}

Listing of cell suppliers, cell areas and number of cell samples measured.

\begin{tabular}{llll}
\hline Supplier & Cell type & $\begin{array}{l}(\text { Total) Cell area } \\
\left(\mathrm{cm}^{2}\right)\end{array}$ & $\begin{array}{l}\text { Number of } \\
\text { tested samples }\end{array}$ \\
\hline A & Mono c-Si & 243.36 & 18 \\
B & & 98 & \\
C & & 225 & 23 \\
D & 3.3 & \\
E & Multi c-Si & 225 & \\
F & & 225 & \\
G & & 243.36 & \\
H & & 243.36 & \\
\hline
\end{tabular}


composition of irradiance may be induced. Wavelength-dependent absorption graphs of the filters showed less than $1.2 \%$ relative deviation in wavelength-resolved absorption. This value is below the spectral mismatch of the used light source compared to the AM 1.5 spectrum, and is therefore assumed negligible.

Irradiance intensity was calculated from the measured shortcircuit current $I_{S C}$ of a calibrated mc-Si (ECN) and c-Si (UU) reference cell assuming $I_{S C}$ to be directly proportional to light intensity $(G)$ in the used range:

$G=\frac{I_{S C, r e f}(G)}{I_{S C, r e f}(G=1000)}=\frac{J_{S C, r e f}(G)}{J_{S C, r e f}(G=1000)}$

where $I_{S C \text {, ref }}(G)$ is the short-circuit current and $J_{S C \text {, ref }}(G=1000)$ is the short-circuit current density at $1000 \mathrm{~W} / \mathrm{m}^{2}$. It is thus assumed that the photo-generated current density $J_{P h}$ is much larger than the saturation current density of the reference cells. The $J V$ curve characteristics (maximum power point voltage $V_{M P}$ and current density $J_{M R}$ open cell voltage $V_{O C}$, short-circuit current density $J_{S C}$ ) were determined to test for reproducibility of the measurements. In addition, $J V$ curves were also measured at dark conditions to derive unbiased shunt resistances of each sample from the linear slope of the reverse dark current.

Diode model parameters (photo-generated current $J_{P h}$, diode currents $J_{0,1}$ and $J_{0,2}$, diode ideality factors $n_{1}$ and $n_{2}$, series and shunt resistances $R_{S e}$ and $R_{S h}$ ) were determined by fitting the measured $J V$ curves using the software tool IVFit [35]. This tool accounts for noise in the current as well as in the voltage signal of the measured datasets: orthogonal distance regression (ODR) algorithms process both the error signal of the current and of the voltage close to $J_{S C}$ and $V_{O C}$ [36]. We cross-checked noise levels that the IVFit tool determined in 'automatic' mode by separate fitting routines and adapted the noise level (if required) such that the single $J V$ curve fit at STC irradiance intensity proved to be as accurate as possible. For all resulting fits the signal-to-noise ratios were never below 100, showing that measurement inaccuracies are in fact negligible. It is nonetheless worthwhile to note that the efficiency of the reference cell that was used at ECN for measuring the 41 commercially manufactured cells was shown to vary quite considerably. Differences of measured efficiency were as high as $1.3 \%$ relative for this reference cell when measured at other leading institutes [37]. However, concerning the measured cell performances presented in this paper the short-circuit current of the reference cell is of interest, not its efficiency, and the same equipment was used during a short period of time. Hence, constant offset errors, such as a spectral mismatch of the light of the sun simulator to AM 1.5 spectrum, can be assumed to remain constant throughout measurements and are consequently 'filtered out'.

The error related to the UU reference cell (calibrated at NREL) can be as high as $3 \%$, so data points shown in the following (e.g. in Fig. 2) can have a systematic relative error of $3 \%$ regarding irradiance intensity (i.e., the $x$-values in Fig. 2). Another error source is the lateral variation in intensity of the light beam, which is also in the order of $3 \%$ (and is also related to $x$-values). However, these errors not only affect the measured data points but also the modelled efficiency and voltages (see modelling results in Section 4 ). Therefore, the $x$-axis distance between modelled and measured data is not affected by these error margins. The only relevant uncertainty is the one of the current and voltage measurements of the measured solar cell itself. For the used measurement equipment (Keithley Model 238 Source Measure Unit) very low uncertainties result: the current and voltage signal of the mc-Si cell at light intensities as low as $0.04 \mathrm{~W} / \mathrm{m}^{2}$ can be measured as accurately as $0.18 \%$ and $0.12 \%$, respectively. We suggest that such errors can be neglected and any further error analysis is omitted.

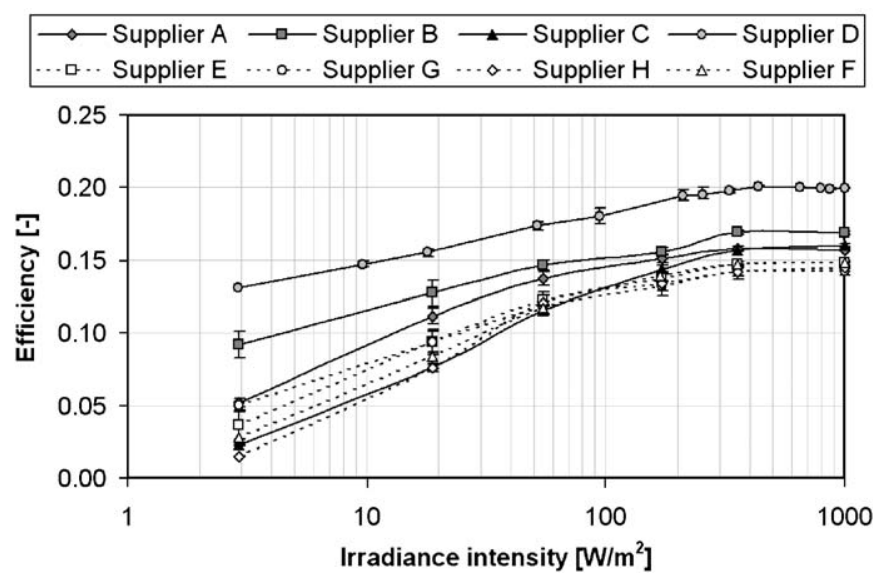

Fig. 1. Measured efficiency as function of irradiance intensity $\left(3-1000 \mathrm{~W} / \mathrm{m}^{2}\right)$ for mono- and multi-crystalline silicon solar cells of eight different solar cell manufacturers.

\subsection{Commercial cell measurements}

The measured irradiance intensity-dependent efficiencies of the 41 commercially produced cells are shown in Fig. 1 for both c$\mathrm{Si}$ and mc-Si cell types. As irradiance intensity is depicted logarithmically, the irradiance intensities usually of concern for PV systems operated outdoors are depicted by only the rightmost irradiance intensity decade.

Efficiencies in this highest irradiance decade $\left(100-1000 \mathrm{~W} / \mathrm{m}^{2}\right)$ are almost constant, and mono- (c-Si) samples outperform multi(mc-Si) cells, as expected. For some of the samples the efficiency between 100 and $1000 \mathrm{~W} / \mathrm{m}^{2}$ is somewhat larger than at STC irradiance intensity. This efficiency increase toward lower intensity can be explained by series resistance effects, as a lower current leads to quadratically lower series resistance loss.

In the lower irradiance decades $\left(1-10-100 \mathrm{~W} / \mathrm{m}^{2}\right)$ the efficiency decreases logarithmically, because $V_{O C}$ is logarithmically dependent on $J_{S C}$. Due to the logarithmic irradiance scale, the apparent linear relationship between efficiency and irradiance intensity can be seen for all of the eight sample sets from different cell manufacturers (intensity decades $1-10-100 \mathrm{~W} / \mathrm{m}^{2}$ ). The measured efficiency at the lowest irradiance of around $3 \mathrm{~W} / \mathrm{m}^{2}$ shows the highest difference, with the highest absolute difference obtained for C-Si suppliers A and C, namely from 2.3\% (C) to $13.1 \%$ (A) absolute percent, and for mc-Si from $1.5 \%$ (supplier $\mathrm{H}$ ) to $5.9 \%$ (supplier E) absolute percent. Moreover, we found that cells from one and the same manufacturer show large differences in cell efficiencies at low irradiance intensity, as an example two mc-Si samples of supplier E: With almost the same performance under STC conditions ( $14.7 \%$ and $14.8 \%$ absolute, respectively) these cells may even belong to the same power-rating class. For these two cells (not shown in the graph), the relative difference in efficiency increases from $1 \%$ at STC conditions to $>200 \%$ (efficiencies of $2.8 \%$ and $5.9 \%$ absolute) at $3 \mathrm{~W} / \mathrm{m}^{2}$ irradiance intensity.

\subsection{Single-cell measurement}

Fig. 2a, b shows the irradiance intensity-dependent $J V$ characteristics of the single mc-Si solar cell (efficiency, opencircuit voltage and fill factors as well as the differential resistances at $V_{O C}$ and $J_{S C}$, respectively, denoted apparent resistances $R_{O C}$ and $R_{S C}$ ) measured between 0.04 and $1000 \mathrm{~W} / \mathrm{m}^{2}$ irradiance intensity. It is found that both open-circuit voltage and the efficiency (Fig. 2b) reach rather low values for this cell. Both parameters 
a

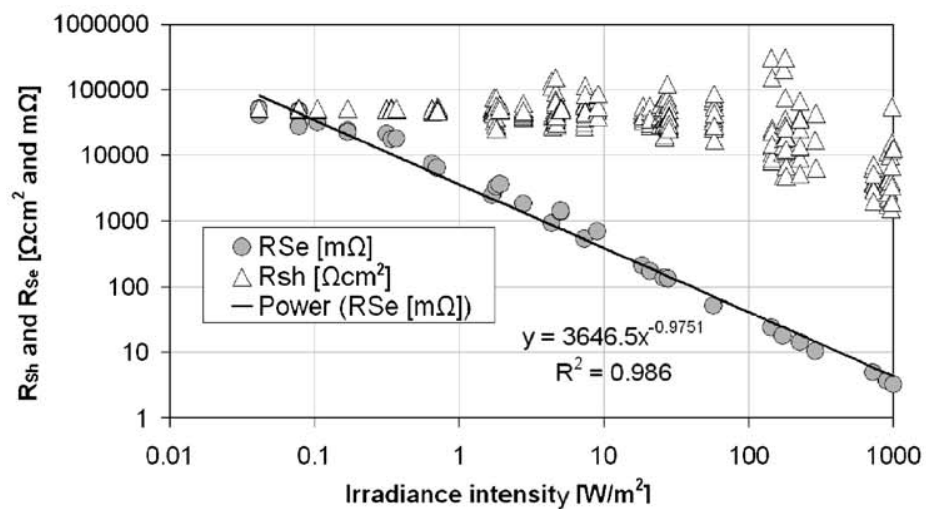

b

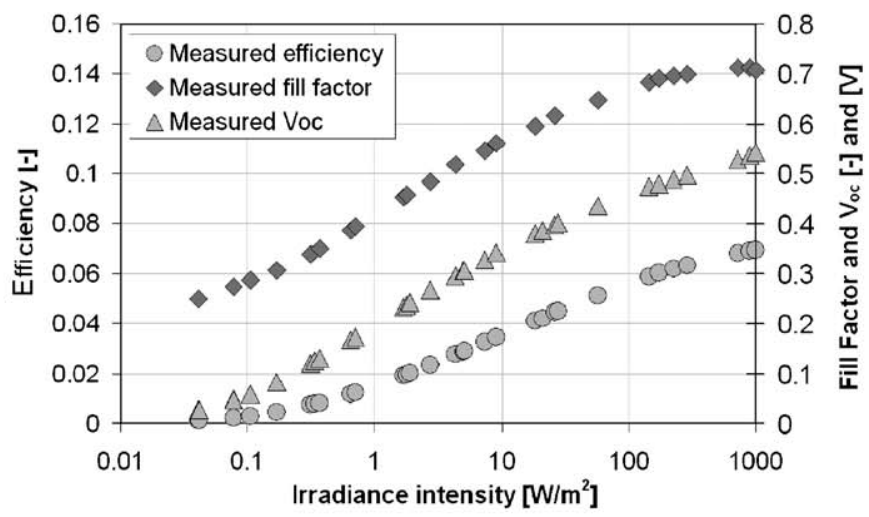

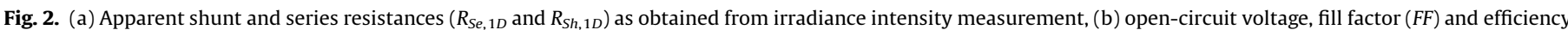
at maximum power point voltage measured between 0.01 and $1000 \mathrm{~W} / \mathrm{m}^{2}$ irradiance intensity for the mc-Si cell.

decrease logarithmically over the whole intensity range, from an intensity of one sun on already.

The resistances shown in Fig. 2a are denoted 'apparent' resistances, as a fitting routine at the UU measurement site that calculates the differential resistances at $V_{O C}$ and $J_{S C}$ was used. The depicted resistances therefore do not necessarily exist in physical terms. Clearly, however, high variations of the differential resistance associated to apparent shunt resistances only occur at high irradiance intensities. This shows that accurate shunt resistance determination is difficult from $I V$ curves of illuminated solar cells. Uncertainty decreases, however, towards weaker light. At very low light intensities, the apparent shunt resistance converges towards a shunt resistance around that of the unbiased shunt resistance measured at dark conditions $\left(R_{S h, \text { dark }}=30 \mathrm{k} \Omega\right.$ $\mathrm{cm}^{2}$ for this specific mc-Si cell).

For the apparent series resistance a power law $\left(R_{S e}=a G^{b}\right)$ applies, with $b$ close to -1 . The good fit of the apparent series resistance to this power function, however, does not mean that a decreasing resistance physically exists. Nonetheless, apparent series resistance reflects the differential resistance of the diode at $V_{O C}$, which is thus the theoretical upper limit of the real series resistance.

\section{Modelling approaches and methods}

\subsection{General approach}

From the research background of this study it is clear that the approach to model performances should meet two requirements:

(a) The energy output should be predicted with reasonable accuracy for irradiances between 1 and $1000 \mathrm{~W} / \mathrm{m}^{2}$ (N.B.: typical irradiation indoors is between 1 and $100 \mathrm{~W} / \mathrm{m}^{2}$, see Ref. [38]).

(b) The specific model should need only a limited set of parameters, either already available from standard cell testing or obtained with only limited extra effort.

Clearly, the solar cell diode model(s) should be selected for further evaluation, as these are widely applied for electrical PV characterisation. Other approaches we evaluated are well-known semiempirical fill factor expressions and a purely empirical approach.

\subsubsection{The one-diode and the two-diode models}

Solar cells are often characterized based on the one diode (1D) model, in which just a single diode current and one single ideality factor account for different physical effects that occur in a solar cell, lumped into one single parameter. Although the accuracy that can be reached with the 1D model is sufficient for fitting a single $J V$ or $I V$ curve, it is not possible to distinguish between different contributions of specific loss currents occurring in solar cells. In the twodiode (2D) model, two different diodes account for recombination within the neutral regions of the cell (the emitter and the bulk, the 'first' diode) and the space charge region(s) (the 'second' diode) separately. With the diode representing recombination in emitter and bulk governed by diffusion and not drift, the "first" diode current density can be accounted for by

$J_{D 1}=J_{0,1}(T)\left[\exp \left(\frac{V_{\text {junction }}}{n_{1} V_{T}}\right)-1\right]$

where $J_{0,1}(T)$ is the saturation current density, $V_{\text {junction }}$ is the junction voltage, $V_{T}=k_{B} T / q$ is the thermal voltage, $T(\mathrm{~K})$ is the absolute temperature, $k_{B}$ is the Boltzmann's constant $\left(1.38 \times 10^{-23} \mathrm{~J} / \mathrm{K}\right), q$ is the elementary charge $\left(1.602 \times 10^{-19} \mathrm{C}\right)$ and $n_{1}$ is the ideality factor, which is supposed to equal 1 due to diffusion-type charge carrier collection. At STC the temperature equals $298.15 \mathrm{~K}$ and hence the thermal voltage $25.67 \mathrm{mV}$.

Accordingly, the saturation current density and ideality factor of the "second" diode can be written as

$J_{D 2}=J_{0,2}(T)\left[\exp \left(\frac{V_{\text {junction }}}{n_{2} V_{T}}\right)-1\right]$

Here, $n_{2}$ equals 2 as in to most text books [39,40]. However, as shown by McIntosh et al. [41] and elaborated in detail by Van der Heide [37], a value of 1.8 is valid for a wide range of doping levels. Cells can have higher values of $n_{2}$, e.g. due to cell design or processing problems during manufacture. Note that for the one-diode model two (physically different) diode currents $J_{D 1}$ and $J_{D 2}$ are lumped together yielding a single-diode current and single ideality factor $n$.

Beside diode-related recombination currents, purely ohmic losses occur. For both the one-diode model and two-diode model an ohmic (lumped) shunt resistance $\left(R_{S h}\right)$ may account for leakage currents (denoting ohmic as linearly dependent on cell voltage). Likewise, an ohmic (lumped) series resistance $\left(R_{S e}\right)$ may account for cell conductance properties, with series resistance-related losses quadratically increasing with current. A further distinction in series resistance origins can be made, such as those related to the emitter region (emitter resistivity), front and back side metallization, and contact resistances. However, in this paper we will only consider single lumped series and shunt resistances.

The one-diode and the two-diode models express the current density available for a load connected to a solar cell ( $\left.J_{\text {Load }}\right)$ by the 
sum of all currents of its equivalent circuit diagram (not shown here). In this so-called 'operation equation' or JV characteristics the current density is expressed as a function of operation voltage $(J=f(V))$. Note that the equation of the one-diode model directly results from simply ignoring the term of the 'second' diode, however, with the implications as discussed above:

$$
\begin{aligned}
J_{\text {Load }}= & J_{P h}-J_{0,1}\left[\exp \left(\frac{V+J_{\text {Load }} R_{S e}}{n_{1} V}\right)-1\right] \\
& -J_{0,2}\left[\exp \left(\frac{V+J_{\text {Load }} R_{S e}}{n_{2} V}\right)-1\right]-\frac{V+J_{\text {Load }} R_{S e}}{R_{S h}}
\end{aligned}
$$

Eq. (4) can be easily used to model irradiance intensity effects on cell characteristics, as the photocurrent density $J_{P h}$ linearly depends on irradiance intensity.

To calculate solar cell efficiency, the operation equation must be solved numerically, leading to a fill factor $(F F)$, an open-circuit voltage $\left(V_{O C}\right)$, a maximum power point voltage $\left(V_{M P}\right)$, a shortcircuit current density $\left(J_{S C}\right)$ and maximum power point current density $\left(J_{M P}\right)$. Then the well-known solar cell efficiency equation can be used:

$\eta(G)=\frac{J_{M P} V_{M P}}{G}=\frac{F F J_{S C} V_{O C}}{G}$

If $J_{M P}$ and $J_{S C}$ are assumed to be linearly related to irradiance $G$ (in $\mathrm{W} / \mathrm{m}^{2}$ ), the maximum power point voltage $V_{M P}$ can be expressed as the product of $V_{O C}$ and $F F(G)$, whereas the opencircuit voltage $V_{O C}$ is in principle independent of the series resistance:

$V_{O C}=\frac{n k_{B} T_{0}}{q} \ln \left(\frac{J_{P h}+J_{0}(T)}{J_{0}(T)}\right)$

Note that this may be approximated by $V_{O C}=n k_{B} T_{0} / q \ln \left(J_{P h} / J_{0}\right)$ for $J_{P h} \gg J_{0}$.

With $J_{S C}$ and $J_{P h}$ linearly related to irradiance intensity, an intensity-dependent fill factor $F F(G)$ can be determined. Hence, intensity-dependent performance can be predicted without the operation equation. Results from this approach, however, are only valid as long as the condition $J_{P h} \gg J_{0}$ is fulfilled, which is of relevance for irradiance intensities as low as about $10^{-5}$ suns.

\subsubsection{Semi-empirical fill factor expressions}

Introduced in discussing detailed balance limits of maximum theoretical efficiency by Shockley and Queisser in 1961 [9], the approach that does not use the operation equation to account for irradiance intensity dependent efficiency was further developed by Green [10] and is expressed in well-known empirical equations (Eqs. (7)-(11)). Series resistance $R_{S e}$ and parallel resistance $R_{S h}$, respectively, are correlated to specific fill factors $F F_{R S e}$ and $F F_{R S h}$, the combination of resistance effects is reflected in $F F_{R S e R S h}$. These fill factors are expressed with a normalized open-circuit voltage $v_{O C}$ :

$v_{O C}=\frac{V_{O C}}{(n k T / q)}$

$F F_{0}=\frac{v_{O C}-\ln \left(v_{O C}+0.72\right)}{v_{O C}+1}$

$F F_{\text {Rse }}=F F_{0}\left(1-r_{s}\right)$

$F F_{R s h}=F F_{0}\left[1-\frac{\left(v_{O C}+0.7\right)}{v_{O C}} \frac{F F_{0}}{r_{s h}}\right]$

$F F_{R s e R s h}=F F_{0}\left(1-r_{s}\right)\left(1-\frac{\left(v_{O C}+0.7\right)}{v_{O C}} \frac{F F_{0}\left(1-r_{s}\right)}{r_{s h}}\right)$

Empirical Eq. (9) gives reasonable accuracy for $v_{o c}>10$ and $r_{s}=R_{S e} /\left(V_{O C} / I_{S C}\right)<0.4$. Eq. (10) holds when only shunt resistance is taken into account and is accurate for $r_{S h}=R_{S h} /\left(V_{O C} / I_{S C}\right)>2.5$ and $v_{o c}>10$ [10]. The combined effects of series and shunt resistances are expressed in Eq. (11). We will refer to this method as MFF. Clearly, Eqs. (7)-(11) only determine $F F(G)$, not efficiency. As the short-circuit current is linearly decreasing with irradiance intensity, however, applying Eq. (6) to calculate irradiance intensity-dependent $V_{O C}$ also allows for calculating efficiency (using Eq. (5)).

\subsubsection{A purely empirical approach}

Analytical solutions of the operation equation (4) cannot be derived, because it is an implicit function. Consequently, numerically solving Eq. (4) is required, making it sometimes more convenient to parameterize irradiance intensity-dependent efficiency by a purely empirical equation. A mixed linear/logarithmic function can be used to model irradiance intensity-dependent efficiency, as proposed by Beyer et al. [21] (therefore also known as the Beyer method) using three parameters $a_{1}, a_{2}$ and $a_{3}$ :

$\eta(G)=a_{1}+a_{2} G+a_{3} \ln G$

During analysis (Section 4.2), however, it was found that at low irradiance intensity also negative efficiencies can result using Eq. (12). Therefore we adapted the original phenomenological equation by including another parameter $\left(a_{4}\right)$ in the logarithmic part, to avoid negative efficiencies and improve fitting accuracy at low light intensities:

$\eta(G)=a_{1}+a_{2} G+a_{3} \ln \left(G+a_{4}\right)$

\subsection{Model overview and different diode model methods}

The empirical expressions of the fill factor (modelling approach denoted MFF) and the phenomenological equation (modelling approach denoted MLL) can be used only to fit measured performances. Hence, only the accuracies of these methods will be tested. For the diode model-based approach, however, a variety of possibilities exist to determine diode model parameter sets.

The most straightforward way we considered is to only use one single $J V$ curve that has been measured at STC, and to fit the JV curve by either the one-diode or the two-diode models. This method, in which diode model parameters are determined from only a single STC-based JV curve, is denoted 'MDSTC' (denoting ' $M$ ' for 'method' and ' $\mathrm{D}$ ' for diode).

In order to investigate how far the accuracy of this MDSTC method can be improved, if the unbiased shunt resistance $R_{S h \text {,dark }}$ also is considered, the method denoted 'MDSH' also considers $R_{S h \text {, dark. }}$ As this parameter is derived from the slope of an $I V$ curve measured under dark conditions, only one additional $J V$ curve measurement is required on top of the $J V$ characteristics determined under STC.

Using constant irradiance intensity levels allows for accurately fitting measured and modelled cell efficiencies, as will be shown in Section 4. This method is denoted MDPAR. However, the MDPAR method fits measured cell characteristics rather than predicting cell performances. The method MDPAR is therefore also used as a reference to determine inaccuracies of the methods MDSTC and MDSH.

Alternatively, combining a dark JV curve and the so-called Suns-Voc curve $[42,43]$ of each candidate cell could reduce the amount of measurements needed. However, this approach was omitted, because we opted for $J V$ curve measurements under constant intensity levels rather than under fluctuating irradiance intensity (i.e., using a flasher), and determining Suns-Voc curves would have required manually placing filters in the light path of the sun simulator. 
Table 2

Listing of applied modelling methods to calculate effective efficiencies.

\begin{tabular}{|c|c|c|}
\hline Modelling approach & Name & Description of modelling method \\
\hline Fill factor expressions & MFF & $\begin{array}{l}\text { Irradiance-dependent fill factor } \\
\text { (FF) as introduced by Shockley and } \\
\text { Queisser [9] and further adapted } \\
\text { by Green [10] (see Eqs. (7)-(11)) } \\
\text { applied to measured FF at STC. }\end{array}$ \\
\hline Empirical function & MLL & $\begin{array}{l}\text { Irradiance-dependent efficiency } \\
\text { modelled with three and four } \\
\text { parameters, } a_{1}-a_{4} \text {, and Eqs. (12) } \\
\text { and (13), based on a mixed linear/ } \\
\text { logarithmic, purely mathematical } \\
\text { equation as originally introduced } \\
\text { by Beyer et al. [21] }\end{array}$ \\
\hline \multirow{3}{*}{$\begin{array}{l}\text { One-diode model and two- } \\
\text { diode model (each } \\
\text { diode model used } \\
\text { separately for the three } \\
\text { methods) }\end{array}$} & MDSTC & $\begin{array}{l}\text { Diode model parameters derived } \\
\text { from fitting one } J V \text { measurement at } \\
\text { STC (see Eqs. (2)-(6)) }\end{array}$ \\
\hline & MDSH & $\begin{array}{l}\text { Other diode model parameters as } \\
\text { determined in method MDSTC, but } \\
\text { unbiased shunt resistance derived } \\
\text { from a } J V \text { curve measured under } \\
\text { dark conditions. }\end{array}$ \\
\hline & MDPAR & $\begin{array}{l}\text { Adapted shunt resistance, series } \\
\text { resistance and diode current(s) } \\
\text { such that the best fit of measured } \\
\text { compared to modelled irradiance } \\
\text { intensity-dependent efficiencies } \\
\text { results. }\end{array}$ \\
\hline
\end{tabular}

An overview of the modelling approaches investigated in this study and of the different methods to determine diode model parameter sets is given in Table 2 .

\section{Modelling results}

The modelling approaches listed in Table 2 were evaluated using the measured data for the mc-Si cell as presented above. The following focuses on the accuracy of each approach.

\subsection{Accuracy of the MFF method}

The parameters required as input for the MFF method were derived from a single $J V$ curve measured at STC of the mc-Si cell (see Section 2), using $I_{P h}=144.6 \mathrm{~mA}, I_{D}=6.4 \times 10^{-7} \mathrm{~A}, n=1.69$, $R_{S e}=71 \mathrm{~m} \Omega, R_{S h, \text { STC }}=565 \Omega$ from a one-diode model fit. For this cell it is found that $v_{O C}>10$ holds only for irradiance levels above $\sim 90 \mathrm{~W} / \mathrm{m}^{2}$, and the condition $r_{S h}>2.5$ is not fulfilled below $3 \mathrm{~W} /$ $\mathrm{m}^{2}$. Fig. 3 shows two fits using the MFF method, one that applies a shunt resistance determined at STC and one determined at a dark condition $J V$ measurement $\left(R_{S h, \text { Dark }}=30 \mathrm{k} \Omega \mathrm{cm}^{2}\right)$. Note that the latter fit increases accuracy towards irradiance intensities as low as $10 \mathrm{~W} / \mathrm{m}^{2}$, with inaccurate conditions $\left(v_{O C} \leqslant 10\right)$ illustrated by grey lines. However, the condition $v_{O C}>10$ is not influenced by shunt resistance so that the valid result-range remains above $90 \mathrm{~W} / \mathrm{m}^{2}$.

Furthermore, measured open-circuit voltages can be compared to modelled ones. Clearly, measured voltage decrease is not accurately modelled. Moreover, qualitatively comparing measured to modelled voltages reveals the limitation of a single-diode modelling approach, upon which the MFF method is based: Only a 'perfectly logarithmic' voltage decrease towards weak irradiance intensities can be modelled.

It is clear from the shown fits that the MFF method is not adequate for our purpose. The method is not even capable to

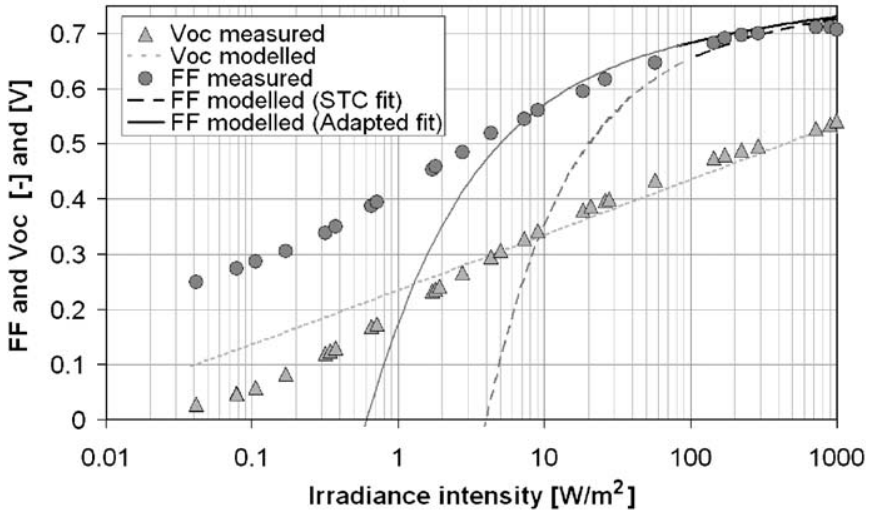

Fig. 3. The measured and modelled $V_{O C}$ and fill factor for the investigated mc-Si cell as a function of the irradiance level (see also Fig. 2).

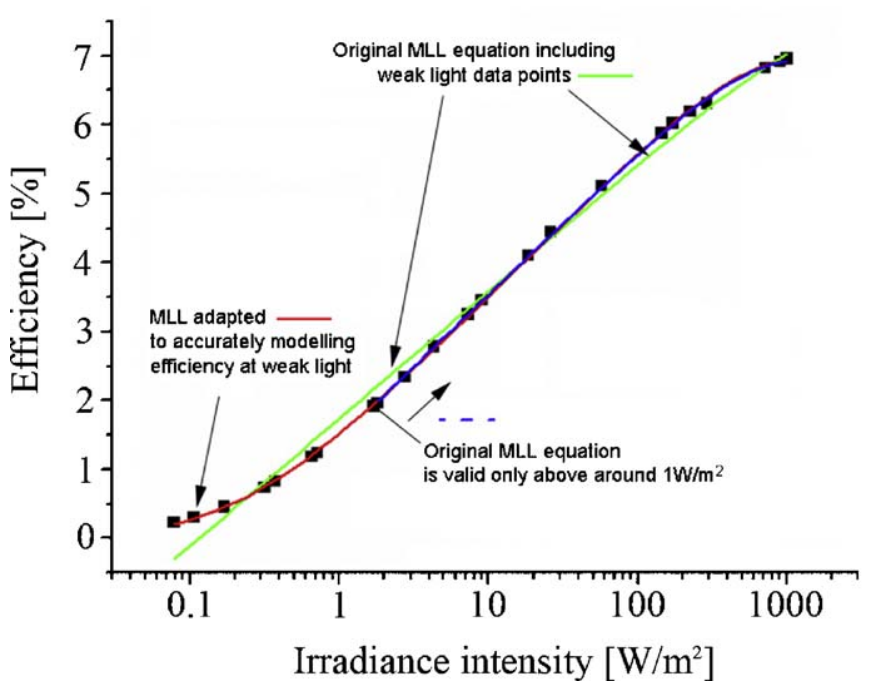

Fig. 4. Fitting the measured efficiency of the irradiance intensity using the original and the adapted equation of the MLL method.

calculate a positive FF for the intensity range $0.1-10 \mathrm{~W} / \mathrm{m}^{2}$. The MFF method will therefore not be considered any further.

\subsection{Accuracy of the MLL method}

A graphical comparison of the original three-parameter (Eq. (12)) and the adapted four-parameter (Eq. (13)) equation is given for fitting performances of the mc-Si cell in Fig. 4. As shown, the original MLL equation may result in negative efficiencies. Clearly, accurate fits result only for irradiance intensity higher than about $1-2 \mathrm{~W} / \mathrm{m}^{2}$. Moreover, the original equation results in a straight line when including measured data below $1 \mathrm{~W} / \mathrm{m}^{2}$ to the fitting routine. By using the new equation that includes a fourth parameter, however, a very good fit results over the entire intensity range. One advantage of this new equation is that checking the domain of the result can be avoided (e.g. within PV simulation tools), because no negative conversion efficiency can result for accurately chosen $a_{4}$.

In conclusion, the MLL method is capable in very accurately simulating irradiance intensity-dependent cell efficiency. However, no predictions can be made using this approach due to the lack of physical parameters. 


\subsection{Accuracy of diode model methods MDSTC, MDSH and MDPAR}

The measured efficiencies as a function of irradiance intensity were fitted by the three methods MDSTC, MDSH and MDPAR for each cell, using both the one-diode and two-diode models. Whereas MDSTC and MDSH methods apply pre-defined parameters, optimized diode model parameter sets have been determined using the method MDPAR.

To evaluate the accuracy of each method, we calculated a measured absolute error (MAE) in addition to a root-meansquare-error (RMSE), as MAE give more accurate information on the actual deviation of measured compared to modelled efficiencies than RMSE.

When a fit at high intensities increases the MAE, however, this does not necessarily judge fitting accuracy at low light intensities. Therefore, if no weighting is applied, one may argue that the MAE approach is inappropriate to evaluate the accuracy of low light intensity models. However, any method aiming to avoid this inappropriateness would require weighting irradiance intensitydependent efficiencies and correlated power output. In addition, higher scores when efficiency is high at higher irradiance intensities must then be considered, as high efficiency at higher intensity is of course more valuable. Consequently, an irradiation intensity distribution would need to be assumed (as is done in sub-Section 4.5), however, which in turn leads to difficulties in selecting the arguably right irradiation intensity distribution. To this end, we decided to calculate the MAE by the average deviation of modelled compared to measured efficiencies over the whole intensity range, equally accounting for each data point.

The MAE is conveniently given in absolute percent efficiency throughout this paper: e.g., at irradiance intensity $3 \mathrm{~W} / \mathrm{m}^{2}$, the measured efficiency of the mc-Si cell as shown in Fig. 2 is $2.3 \%_{a b s}$ and the modelled efficiency for, e.g., the one-diode model is $1.1 \%_{a b s}$. This $1.2 \%_{a b s}$ difference is represented by an MAE of $1.2 \%_{a b s}$. Note that this translates to a relative error of almost $100 \%$ comparing measured to modelled values.

\subsubsection{Accuracy of models MDSTC and MDSH}

A graphical comparison of measured and modelled characteristics for the mc-Si cell is given in Fig. 5a (MDSTC) and Fig. 5b (MDSH). Measured efficiency and open-circuit voltage are depicted as points; modelling results are depicted as lines.

As the MDSTC modelling method uses parameters solely determined from a $J V$ curve taken under STC, the error for the MDSTC method is relatively high. However, using the two-diode model is better to predict efficiencies than the one-diode model.
An RMSE of $0.23 \%$ and a MAE of $0.2 \%$ abs result for the two-diode model compared to an RMSE of $0.66 \%$ and MAE of $0.51 \%$ abs for the one-diode model.

The MDSH method additionally takes the unbiased shunt resistance determined from a dark $I V$ curve measurement into account. Here, fits are improved with respect to the MDSTC method especially for the one-diode model, showing RMSE $0.32 \%$ and MAE $0.27 \%_{a b s}$. Differences especially in the highest intensity decade of the modelled $V_{O C}$, however, remain. Also for the MDSH method the two-diode model yields a better result than the onediode model (with errors of $0.13 \%$ RMSE and $0.1 \%$ abs MAE). Clearly, employing the two-diode model is preferred.

\subsubsection{Adapting diode model parameters: the MDPAR method}

We also investigated the effect of variation of parameters of both the one- and the two-diode models on solar cell performance as a function of irradiance intensity. Over the whole irradiance intensity range only a single parameter was varied at a time. All other parameters were kept constant. The one-diode parameter starting set was $I_{P h}=36 \mathrm{~mA} / \mathrm{cm}^{2}, R_{S e}=0.826 \mathrm{~m} \Omega \mathrm{cm}^{2}, R_{S h}=2 \mathrm{k} \Omega$ $\mathrm{cm}^{2}, I_{D}=6 \times 10^{-7} \mathrm{~A}, n_{1}=1$.

Series resistance effects were investigated first. The series resistances of $156 \times 156 \mathrm{~mm}^{2}$ crystalline silicon solar cells that have screen printed front side metallization is usually above $1 \Omega \mathrm{cm}^{2}$ but they can be reduced to values less than $0.3 \Omega \mathrm{cm}^{2}$ using photolithography [44]. Series resistances can be much larger for thin film devices $[13,14]$. We chose to model series resistance effects between 0.008 and $14 \Omega \mathrm{cm}^{2}$, as shown in Fig. 6a. Although upper and lower values have been chosen to be rather extreme (i.e., industrially produced crystalline silicon cells rarely have series resistances above $2 \Omega \mathrm{cm}^{2}$ ), the effect of series resistance on cell performance is clearly limited to the highest irradiance decade only (100-1000 W/ $\mathrm{m}^{2}$ ). At irradiance intensity below $100 \mathrm{~W} / \mathrm{m}^{2}$ generated currents are too small to cause noticeable resistive losses.

Second, we investigated the influence of shunt resistance by varying it between 0.5 and $10 \mathrm{k} \Omega \mathrm{cm}^{2}$ (Fig. 6b). It is clear that, in contrast to series resistance effects, the shunt resistance is particularly influential in lower irradiance intensities.

Third, the effect of varying the ideality factor $n$ of the onediode model was analyzed, as shown in Fig. 6c. Note that the influence of the diode current is significant only when in the maximum power point the diode current is larger then the current due to the shunt resistance. In the specific case shown, the influence of the diode part is limited to values corresponding to irradiance intensity larger than $10 \mathrm{~W} / \mathrm{m}^{2}$. For higher shunt resistances, the influence of diode recombination (and thus also a

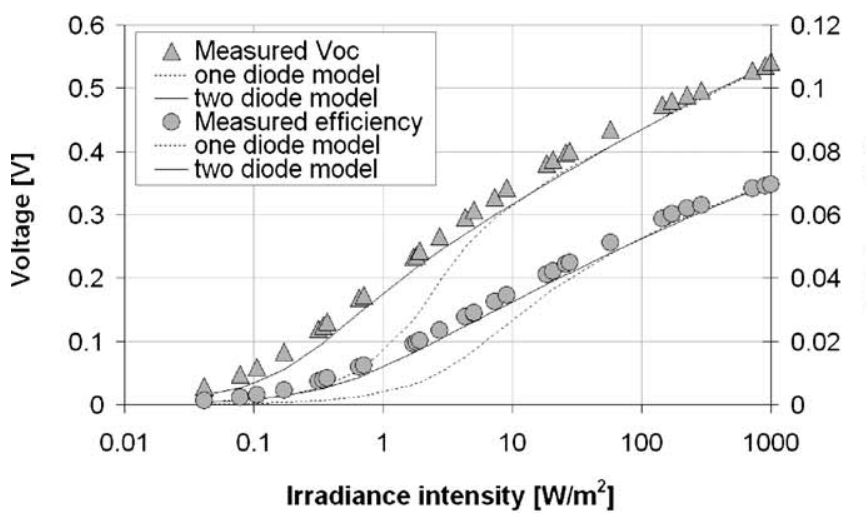

b

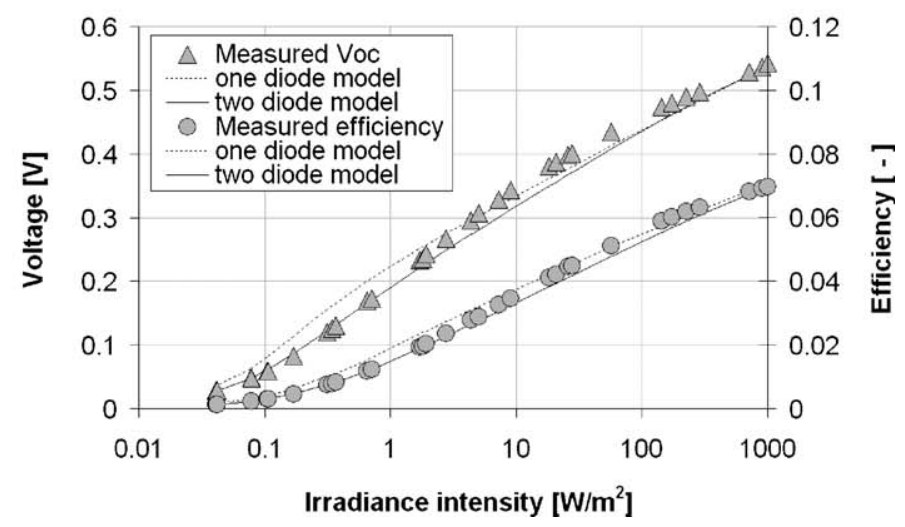

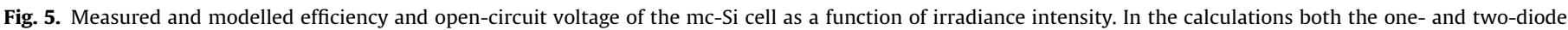
model was applied using methods (a) MDSTC and (b) MDSH. 

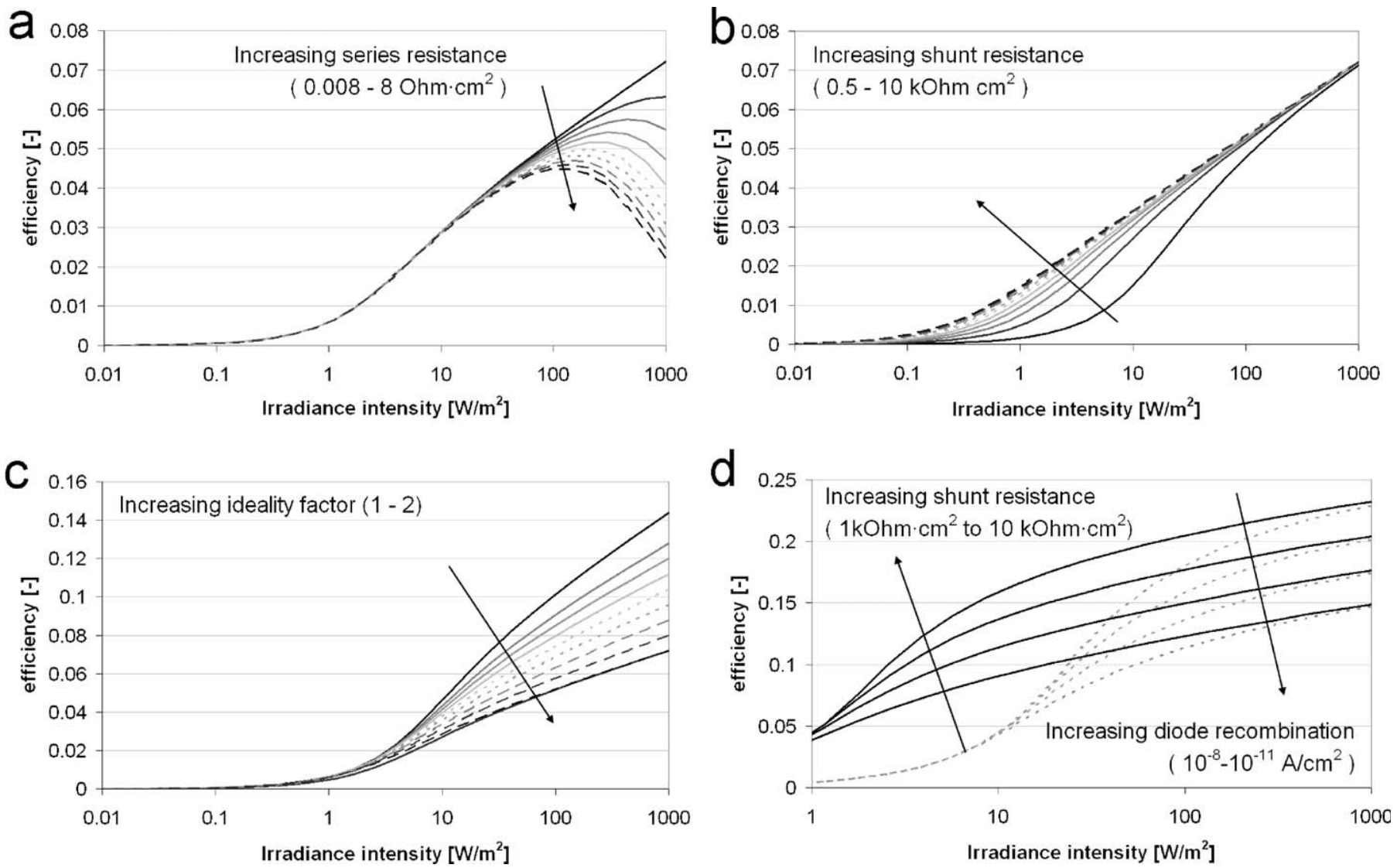

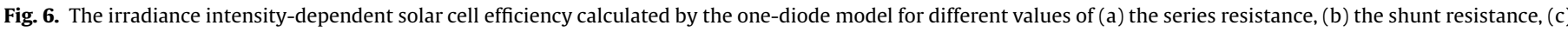
the ideality factor (which gives comparable results for different diode currents) and (d) combined effect of different diode currents and shunt resistances.

the diode ideality factor $n$ ) extends towards lower intensities. To this end, a very high shunt resistance would be particularly useful for cells operated under predominantly low light intensities.

Sufficiently high shunt resistances, however, only make sense if the photo-voltage to be sustained is reasonably high, which in turn requires diode currents as low as possible. This is illustrated in Fig. 6d, which shows modelled efficiency as a function of intensity for a variety of diode currents between $10^{-8}$ and $10^{-11} \mathrm{~A} /$ $\mathrm{cm}^{2}$ and two shunt resistances $R_{S h}=1 \mathrm{k} \Omega \mathrm{cm}^{2}$ and $R_{S h}=10 \mathrm{k} \Omega$ $\mathrm{cm}^{2}$ using the 2D model parameter set $I_{P h}=42 \mathrm{~mA} / \mathrm{cm}^{2}, R_{S e}=0.2$ $\mathrm{m} \Omega \mathrm{cm}^{2}, n_{1}=1.2$ and $n_{2}=1.8$. Clearly, lower diode currents are favourable in principle, however, the shunt resistance is of differing influence at each different diode current.

Finally, diode model parameters were varied such that an optimal fit of measured compared to modelled cell efficiencies as a function of irradiance intensity resulted (method MDPAR). This fit for the mc-Si cell (as previously shown in Fig. 2) is depicted in Fig. 7. The fitting accuracy is very much improved to MAE of $0.07 \%_{a b s}$ (1D) and $0.03 \%_{a b s}$ (2D) absolute. Although the error is rather small for the one-diode model, a systematic error can be discerned. As shown in Fig. 7 in the upper right part, the opencircuit voltage can only be modelled such that a linear voltage decrease on the logarithmic plot results with the one-diode model, whereas the two-diode model accounts for the S-shaped voltage decrease by the second diode current and ideality factor in the exponential part. Thus, open-circuit voltage at STC conditions is overestimated for the one-diode model parameter set that has been fitted with regard to efficiency. Again, as was already stated for the MDSTC and MDSH methods, employing the two-diode model is preferred.

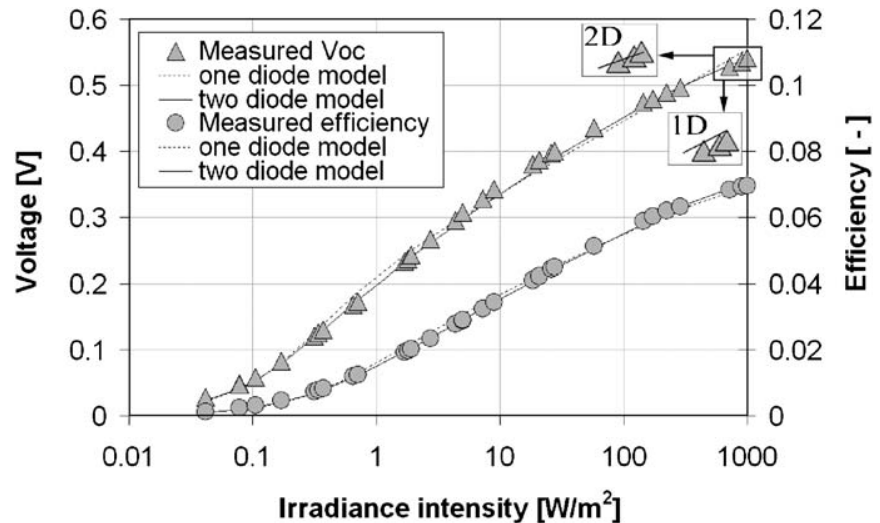

Fig. 7. Optimized fit of the irradiance intensity-dependent solar cell efficiency for the mc-Si cell by applying the MDPAR method for the one-diode (1D) and the twodiode (2D) model.

\subsection{Modelling commercial cells with methods MDSTC, MDSH and MDPAR}

Table 3 presents resulting accuracies in the form of averaged measured absolute errors (MAE) grouped per supplier for the respective modelling methods. The given standard deviation is calculated per supplier, with at least three cells measured (see Table 2). As is clear from Table 3, the method that uses an unbiased shunt resistance (MDSH) provides better results than the MDSTC method, except for samples from supplier $C$. This as well as the excellent fits of suppliers C $\left(0.14 \%_{a b s}\right)$ and $\mathrm{H}\left(0.12 \%_{a b s}\right)$ 
for the MDPAR method are related to the fact that the starting parameter set (i.e., STC parameters) has been closer to the resulting parameter set; this can be inferred from the already low MAE for the MDSTC method.

\subsection{Effective efficiencies}

Having determined which method is best in terms of accuracy for modelling irradiance intensity-dependent efficiency, it is now shown what effects different cell performances at varying intensities have on energy yield. To this end, a scenario for the annual irradiation intensity distribution is assumed, in order to simulate the theoretical energy yield-exclusively with respect to their irradiance intensity-dependent performance-of the measured crystalline silicon solar cells. We selected an outdoor irradiance intensity distribution, which is based on hourly averaged horizontal irradiation measured in de Bilt, the Netherlands, in 2005. The 'effective efficiency' $\eta_{\text {eff, } G}$ with respect to just different irradiation intensities $G\left(h_{i}\right)$ is defined by

$\eta_{e f f, G}=\frac{\sum_{i} G\left(h_{i}\right) \eta\left(G\left(h_{i}\right)\right)}{G_{a}}$

with $G_{a}=\sum_{i} G\left(h_{i}\right)$ the annual $(8760 \mathrm{~h})$ irradiation sum. This permits for an appropriate weighting of irradiance-dependent efficiencies and the correlated power output, attributing higher scores when the efficiency is high at higher irradiance intensities.

Table 3

Measured absolute error (MAE) for the best fit of the methods MDSTC, MDSH and MDPAR for crystalline silicon solar cells from eight suppliers (A-H), indicating accuracies.

\begin{tabular}{|c|c|c|c|}
\hline \multirow[t]{2}{*}{$\begin{array}{l}\text { Cell supplier } \\
\text { code }\end{array}$} & \multicolumn{3}{|c|}{$\begin{array}{l}\text { Measured absolute error (MAE) of the cell efficiency } \\
(\% \text { absolute }) \text { for fits of the investigated methods compared to } \\
\text { measured results }\end{array}$} \\
\hline & MDSTC & MDSH & MDPAR \\
\hline A & $2.6 \pm 0.3$ & $0.7 \pm 0.2$ & $0.27 \pm 0.12$ \\
\hline B & $2.0 \pm 0.3$ & $0.4 \pm 0.1$ & $0.25 \pm 0.06$ \\
\hline C & $0.4 \pm 0.3$ & $1.4 \pm 0.1$ & $0.14 \pm 0.04$ \\
\hline D & $0.7 \pm 0.2$ & $0.5 \pm 0.1$ & $0.27 \pm 0.08$ \\
\hline $\mathrm{E}$ & $1.4 \pm 0.3$ & $0.5 \pm 0.2$ & $0.26 \pm 0.06$ \\
\hline $\mathrm{F}$ & $1.7 \pm 0.2$ & $1.0 \pm 0.1$ & $0.30 \pm 0.01$ \\
\hline G & $1.7 \pm 0.6$ & $0.4 \pm 0.3$ & $0.24 \pm 0.15$ \\
\hline $\mathrm{H}$ & $0.6 \pm 0.3$ & $0.5 \pm 0.1$ & $0.12 \pm 0.04$ \\
\hline
\end{tabular}

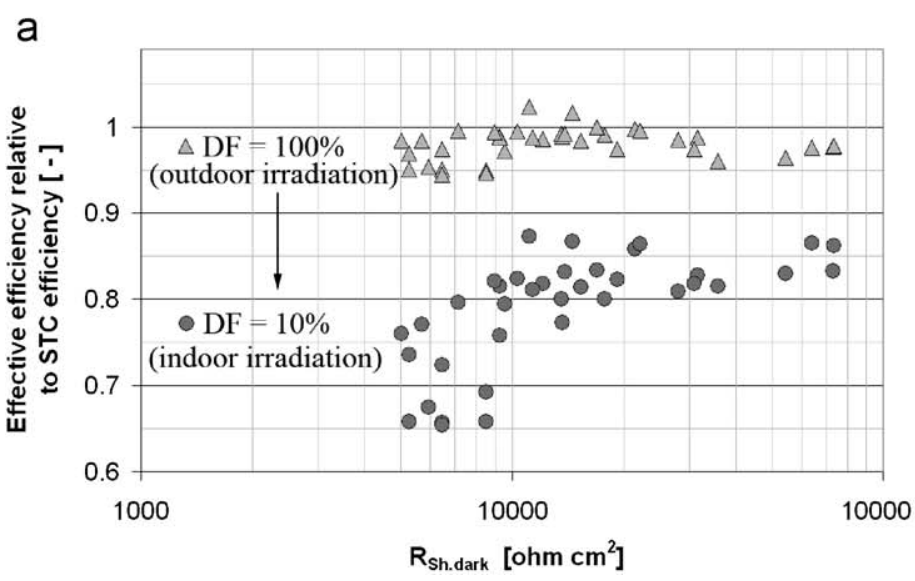

As the tested cells could well be applied in PIPV operated indoors, we also used a simplified indoor irradiance intensity distribution by assuming a constant daylight factor (DF) of $10 \%$, i.e., indoor intensities are exactly $10 \%$ of the outdoor ones, including direct beam intensities.

It is recognized that these irradiation scenarios and the assumptions concerning solar cell performances oversimplify (indoor) irradiation conditions and PV power output that will occur in practice. Neither a spatial distribution of incident irradiance nor other spectra of the (indoor) light are taken into account. Also incident angle-dependent reflection is neglected. Moreover, we consider cells that are not encapsulated. Nonetheless, the approach to calculate the 'effective' efficiency as an overall performance parameter allows ascertaining the influence of specific low light performance parameters on energy yield. In particular it allows comparing the performance of the cells relative to STC efficiency.

The shunt resistance is an important parameter affecting the efficiency of solar cells at low light intensities. The unbiased shunt resistance $\left(R_{S h \text {, dark }}\right)$ can be easily determined from dark JV curve measurements. Therefore, we have plotted the ratio between the effective efficiency as a function of the $R_{S h \text {,dark }}$ parameter, see Fig. 8. The resulting performances relative to STC vary between $94 \%$ and $102 \%$ for the simplified outdoor compared to $65 \%$ and $87 \%$ for the simplified indoor irradiation intensity distribution.

To compile the data points shown, we applied the two-diode model parameter sets of the 41 cells using the MDPAR method. A strong correlation between the low light performance of the cells and $R_{S h \text {,dark }}$ would make the classification of cells relatively easy, i.e., sorting of cells not only by different power classes but also with respect to $R_{S h \text {, dark. }}$. As can be seen in Fig. 8, however, cells that show a low $R_{S h \text {,dark }}$ exhibit only a somewhat lower effective efficiency. Consequently, a higher $R_{S h \text {,dark }}$ not necessarily yields better effective efficiency, except for the cells from supplier E (see filled triangles). Although a tendency of correlation is found, we suggest that the spread in diode currents of the cells is too large to allow for sorting cells based on their shunt resistance only.

\section{Discussion}

The obtained modelling results show that quite accurate predictions of the energy that can be harvested by the commercially available, crystalline silicon solar cells can be made using

b

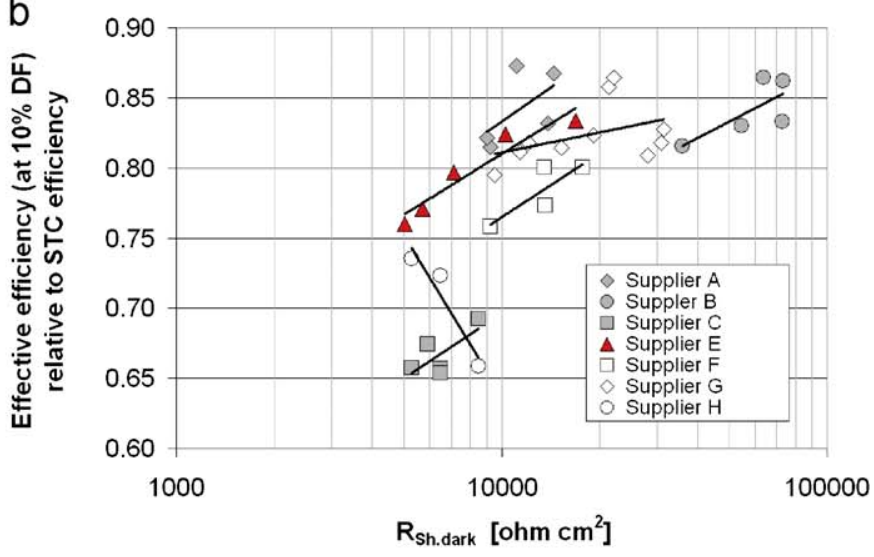

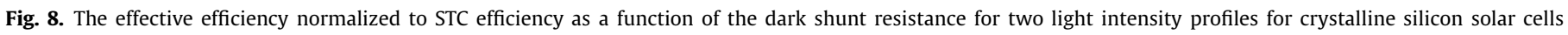

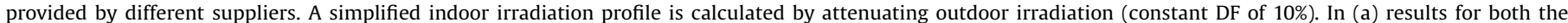
outdoor and the simplified indoor irradiation profile and in (b) only results related to the indoor profile are shown. 
both the one-diode and the two-diode models. However, several limitations exist in our approach when calculating the presented 'effective' efficiency of the commercial cells. They require further attention and are briefly discussed in the following.

Furthermore, why thin film solar cells have not yet been considered will be discussed, and we also discuss how far the shunt resistance determined from dark JV curve measurements may help to increase the accuracy in determination of other diode model parameters.

\subsection{Limitations and further modelling requirements}

Several effects and parameters have not been considered when determining 'effective' efficiencies: Neither the effect of temperature on energy yield nor the influence of different spectral compositions of irradiation have been accounted for, and other effects on solar cell performance such as incident angle dependency of irradiance and corresponding reflections were omitted. Moreover, we did not consider cell encapsulation.

However, although the outdoor performance is strongly affected by ambient and module temperature, this is hardly the case if low light intensities prevail. Outdoor PV module temperatures lead to a decrease of $10-20 \%$ the annual energy yield compared to the yield estimated at constant temperature $25^{\circ} \mathrm{C}$. In case of indoor PV, however, the ambient temperature is rather constant (normally $15-25^{\circ} \mathrm{C}$ ) and temperature effects will be very small, as the irradiation is low (e.g., due to window absorption). In turn, spectral effects gain importance.

Whereas spectral effects are generally much less than temperature effects for crystalline silicon-based PV systems operated outdoors, spectral effects on indoor PV performance should be carefully accounted for. Calculated by measured spectral response (SR) of the 41 cells, different window glazing types can cause the short-circuit current to decrease with a $15 \%$ difference for cells of same type but from different manufacturers.

\subsection{Required future research on different types of solar cells}

Thin film solar cells have not been included in this study, as more complex physical phenomena would needed to be taken into account. Due to voltage-dependent photocurrent collection $[11,26]$ and recombination rate [12] as well as different ideality factor modelling requirements [45] the superposition principle, which means that the model elements are completely independent, is not necessarily valid. However, Hegedus presented modelling of a-Si and Si-Ge [11] and recently also cadmium telluride (CdTe)-based cells [26] accounting for voltage-dependent photocurrent collection. Virtuani et al. [20] already presented weak light performance effects when annealing CIGS cells. These findings and results from the VIM method as presented by Merten et al. [33,34] actually allow modelling of thin film devices as a function of irradiance intensity. Nonetheless, this modelling is much more complex, and hence we decided in this article to focus on crystalline silicon cells exclusively-for which the superposition principle is well known to hold [46].

Furthermore, crystalline silicon solar cells using different grades of purity in silicon have been excluded in this study. With less pure silicon being a promising route to cut costs of crystalline silicon solar cells, such cells may also be an interesting option regarding PIPV, particularly from an economical perspective. On the other hand, the weak light performance of such cells is supposedly (much) lower, due to the low shunt resistances one can expect for those solar cells. Reasonable large shunt resistances, however, are a prerequisite for good solar cell performances at low light, as presented.

\subsection{The unbiased shunt resistance as a low light performance indicator}

The unbiased shunt resistance as a performance indicator at low light intensities has been evaluated in the Results section. However, it was shown that shunt resistance effects are superimposed by diode current and series resistance effects. Nonetheless, especially the 15 cells with a shunt resistance below $10 \mathrm{k} \Omega \mathrm{cm}^{2}$ do not perform well (on average 'effective' efficiency is $72 \%$ on average compared to the STC efficiency) compared to cells with a shunt resistance larger than $10 \mathrm{k} \Omega \mathrm{cm}^{2}$ ('effective' efficiency being $83 \%$ on average compared to STC efficiency).

Particularly for the outdoor irradiation scenario, however, the correlation between $R_{S h \text {, dark }}$ and the 'effective' efficiency is not so clear, which is due to the fact that in this intensity range the series resistance effects dominate. Moreover, as the low light performance is not determined by shunt resistance alone but by shunt resistance in combination with specific diode currents, accurate determination of diode currents is of particular importance.

With series resistance effects superimposing diode characteristics at irradiance intensities close to STC, required accuracy levels may not be reached. Hence, although series resistance has no effect on low light performance, accurate determination of series resistance would help increasing prediction accuracy of the low light performance of solar cells, simply because more accurate determinations of diode currents become possible if the (lumped) series resistance is known.

An even more promising way to determine diode currents, however, is to first measure the unbiased shunt resistance only: if the unbiased shunt resistance is derived first, at dark conditions, the upper diode current could be determined more accurately by measuring the increase of open-circuit and maximum power point voltages as a function of irradiance intensity. This approach is quite similar to the VIM method as proposed by Merten et al. [33], but it would require less measurements, at a very narrow intensity range, compared to the original VIM method once $R_{S h \text {,dark }}$ is determined. As in the concerned irradiance intensity range no series resistance effects occur, diode currents could be determined more accurately. However, once $R_{S h \text {, dark }}$ has been determined it would have to be stimulated how voltages are expected to increase with specific diode currents.

\section{Conclusions}

The performance of crystalline silicon solar cells in dependence of irradiance intensity (much) lower than one sun was investigated. This is of special importance for solar cells incorporated into PV powered products which are used predominantly indoors.

To evaluate the accuracy of four model approaches to predict the intensity-dependent solar cell performance, we measured the performance of 41 industrially manufactured cells from eight suppliers at six different light intensities and one single multicrystalline silicon solar cell at many light levels. Based on this experimental data, the accuracies of the following four modelling approaches were evaluated: (1) empirical fill factor expressions, (2) a purely empirical function, (3) the one-diode model and (4) the two-diode model. The results show that fill factor expressions and the empirical function fail at low light intensities, but a new empirical equation could be derived to accurately fit efficiency also at low light.

Accuracies of both diode models are very high. However, the accuracy highly depends on the used diode model parameter sets. Therefore, different methods to determine diode model parameter sets and the corresponding modelling accuracy that can be 
obtained were compared. The two-diode model is found to be preferred in principle: particularly its capability in accurately modelling $V_{O C}$ and not just the efficiency, with one and the same parameter set, makes the two-diode model superior. Average fitting errors of only $0.07 \%$ abs (for the one diode model) and $0.03 \%_{a b s}$ (for the two diode model) were obtained for fitting measured single-cell performance in an irradiance intensity decade that covers five orders of magnitude.

The irradiance intensity-dependent performance of the commercial cells was measured and fitted between 3 and $1000 \mathrm{~W} / \mathrm{m}^{2}$. Knowing the low light performance, the so-called 'effective' efficiency of these cells was calculated. Two simplified irradiance intensity distributions were used, disregarding other effects on performance such as spectra, incident angle of irradiance, reflection, cell encapsulation and temperature. The resulting performances relative to STC varied from $94 \%$ to $102 \%$ for a simplified outdoor compared to $65 \%$ and $87 \%$ for a simplified indoor irradiation intensity distribution. To avoid low-energy yields of cells used under predominantly low irradiance intensities the results suggest a lower limit of shunt resistance measured at dark conditions of $10 \mathrm{k} \Omega \mathrm{cm}^{2}$.

\section{Acknowledgements}

We would like to thank the many PV cell manufacturers who generously supplied numerous samples of their commercially available solar cells. This work is financially supported by the NWO-SenterNovem Energy Research programme.

\section{References}

[1] E.A. Alsema, B. Elzen, N.H. Reich, W.G.J.H.M. Van Sark, S.Y. Kan, S. Silvester, M. Veefkind, J. Jelsma, in: Proceedings of the 20th European Photovoltaic Solar Energy Conference, Barcelona, Spain, 2005, pp. 1981-1984.

[2] N.H. Reich, M. Veefkind, W.G.J.H.M. van Sark, E.A. Alsema, W.C. Turkenburg, S. Silvester, A solar powered wireless computer mouse: industrial design concepts, Solar Energy 83 (2) (2009) 202-210.

[3] N.H. Reich, W.G.J.H.M. van Sark, E.A. Alsema, in: Proceedings of the 21st European Photovoltaic Solar Energy Conference and Exhibition, Dresden, Germany, 2006, pp. 2301-2305.

[4] N.H. Reich, W.G.J.H.M. van Sark, E.A. Alsema, A.H.M.E. Reinders, H. de Wit, in: Proceedings of the 22nd European Photovoltaic Solar Energy Conference, Valencia, Spain, 2008.

[5] N.H. Reich, H. de Wit, A.H.M.E. Reinders, W.G.J.H.M. van Sark, W.C. Turkenburg, Using CAD software to simulate PV energy yield-The case of Product Integrated Photovoltaics operated under indoor solar irradiation, submitted.

[6] N.H. Reich, W.G.J.H.M. van Sark, E.A. Alsema, M.P. Netten, S. Silvester, in: Proceedings of the 22nd European Photovoltaic Solar Energy Conference, Valencia, Spain, 2008

[7] M. Veefkind, N.H. Reich, B. Elzen, S.Y. Kan, S. Silvester, M. Verwaal, E.A. Alsema, W.G.J.H.M. van Sark, J. Jelsma, in: Proceedings of the Going Green-Care Innovation 2006, Vienna, Austria, 2006, pp. 3.6.4.

[8] N.H. Reich, in: Proceedings of the 21st European Photovoltaic Solar Energy Conference and Exhibition, Dresden, Germany, 2006, pp. 2306-2311.

[9] W. Shockley, H.J. Queisser, Detailed balance limit of efficiency of p-n junction solar cells, Journal of Applied Physics 32 (3) (1961) 510-519.

[10] M.A. Green, Solar Cells; Operating Principles, Technology and Systems Application, Prentice-Hall, Englewood Cliffs, NJ, USA, 1982.

[11] S. Hegedus, Current-voltage analysis of a-Si and a-SiGe solar cells including voltage-dependent photocurrent collection, Progress in Photovoltaics: Research and Applications 5 (3) (1997) 151-168.

[12] J. Merten, J. Andreu, Clear separation of seasonal effects on the performance of amorphous silicon solar moduled by outdoor $I / V$-measurements, Solar Energy Materials and Solar Cells 52 (1) (1997) 11-25.

[13] M. Burgelman, A. Niemegeers, Influence of illumination conditions on the design of thin-film modules, Solar Energy Materials and Solar Cells 57 (1998) 85-95.

[14] J.A. del Cueto, Method for analyzing series resistance and diode quality factors from field data of photovoltaic modules, Solar Energy Materials and Solar Cells 55 (3) (1998) 291-297.
[15] J.A. del Cueto, Method for analyzing series resistance and diode quality factors from field data part II: applications to crystalline silicon, Solar Energy Materials and Solar Cells 59 (4) (1999) 393-405.

[16] C. Gemmer, M.B. Schubert, in: Proceedings of the Materials Research Society Symposium, 2001, pp. A25.29.21-A25.29.26.

[17] J.F. Randall, C. Droz, M. Goetz, A. Shah, J. Jacot, in: Proceedings of the 17th European Photovoltaic Solar Energy Conference, Munich, Germany, 2001, pp. 603-606.

[18] J.F. Randall, On the use of photovoltaic ambient energy sources for powering indoor electronic devices, Thesis, Ecole Polytechnique Fédérale de Lausanne, Lausanne, 2003.

[19] J.F. Randall, J. Jacot, Is AM1.5 applicable in practice? Modelling eight photovoltaic materials with respect to light intensity and two spectra, Renewable Energy 28 (12) (2003) 1851-1864.

[20] A. Virtuani, E. Lotter, M. Powalla, Performance of $\mathrm{Cu}(\mathrm{In}, \mathrm{Ga}) \mathrm{Se} 2$ solar cells under low irradiance, Thin Solid Films 431-432 (2003) 443-447.

[21] H.G. Beyer, J. Betcke, A. Drews, D. Heinemann, E. Lorenz, G. Heilscher, S. Bofinger, in: Proceedings of the 19th European Photovoltaic Solar Energy Conference, Paris, France, 2004, pp. 3073-3076.

[22] P. Grunow, S. Lust, D. Sauter, V. Hoffmann, C. Beneking, B. Litzenburger, L. Podlowski, in: Proceedings of the 19th European Photovoltaic Solar Energy Conference, Paris, France, 2004, pp. 2190-2193.

[23] L. Stamenic, E. Smiley, K. Karim, Low light conditions modelling for building integrated photovoltaic (BIPV) systems, Solar Energy 77 (1) (2004) 37-45.

[24] N.H. Reich, W.G.J.H.M. Van Sark, E.A. Alsema, S.Y. Kan, S. Silvester, A.S.H. Van der Heide, R.W. Lof, R.E.I. Schropp, in: Proceedings of the 20th European Photovoltaic Solar Energy Conference, Barcelona, Spain, 2005, pp. 2120-2123.

[25] R.P. Kenny, E.D. Dunlop, H.A. Ossenbrink, H. Müllejans, A practical method for the energy rating of $\mathrm{c}-\mathrm{Si}$ photovoltaic modules based on standards tests, Progress in Photovoltaics: Reearch and Applications 14 (2006) 155-166.

[26] S. Hegedus, D. Desai, C. Thompson, Voltage dependent photocurrent collection in CdTe/CdS solar cells, Progress in Photovoltaics: Research and Applications 15 (2007) 587-602.

[27] M. Topic, K. Brecl, J. Sites, Effective efficiency of PV modules under field conditions, Progress in Photovoltaics: Research and Applications 15 (1) (2007) $19-26$.

[28] F. Nieuwenhout, N. van der Borg, W.G.J.H.M. van Sark, W.C. Turkenburg, A new method for estimating insolation based on PV-module currents in a cluster of stand-alone solar systems, Progress in Photovoltaics: Research and Applications 15 (5) (2007) 387-404.

[29] A.R. Burgers, New metallization patterns and analysis of light trapping for silicon solar cells, Thesis, ECN, Petten, 2005.

[30] P.C. de Jong, D.W.K. Eikelboom, R. Kinderman, A.C. Tip, J.H. Bultman, in: Proceedings of the 19th European Photovoltaic Solar Energy Conference, Paris, France, 2004, pp. 2145-2148.

[31] A.H.M.E. Reinders, V.A.P. van Dijk, E. Wiemken, W.C. Turkenburg, Technical and economic analysis of grid-connected PV systems by means of simulation, Progress in Photovoltaics: Research and Applications 7 (1) (1999) 71-82.

[32] R.E.I. Schropp, M. Zeman, Amorphous and Microcrystalline Silicon Solar Cells: Modeling, Materials, and Device Technology, Kluwer Academic Publishers, Boston, MA, USA, 1998.

[33] J. Merten, J.M. Asensi, C. Voz, A. Shah, R. Platz, J. Andreu, Improved equivalent circuit and analytical model for amorphous silicon solar cells and modules, IEEE Transactions on Electron Devices 45 (2) (1998) 423-429.

[34] J. Merten, L. Sicot, Y. Delesse, A. Guerin de Montgareuil, in: Proceedings of the 22nd European Photovoltaic Solar Energy Conference, Valencia, Spain, 2008.

[35] T. Burgers, IVFIT program, downloadable at 〈http://www.ecn.nl/en/zon/ products-services/i-v-curve-fitting-program-ivfit $/\rangle$.

[36] A.R. Burgers, J.A. Eikelboom, A. Schönecker, W.C. Sinke, in: Proceedings of the 25th IEEE Photovoltaic Specialists Conference, Washington, DC, USA, 1996, pp. 569-572.

[37] van der Heide Aea, in: Proceedings of the 20th European Photovoltaic Solar Energy Conference and Exhibition, Barcelona, Spain, 2005, pp. 2055-2058.

[38] J. Wen, T.F. Smith, Absorption of solar energy in a room, Solar Energy 72 (4) (2002) 283-297.

[39] F. Lasnier, T.G. Ang, Photovoltaic Engineering Handbook, Adam Hilger, 1990.

[40] J. Nelson, The Physics of Solar Cells, Imperial College Press, Distributed by World Scientific Pub. Co., River Edge, NJ, 2003, 363pp.

[41] K.R. McIntosh, P.P. Altermatt, G. Heiser, in: of the Proceedings 16th European Photovoltaic Solar Energy Conference, Glasgow, UK, 2000, pp. 251-254.

[42] M.J. Kerr, A. Cuevas, Generalized analysis of the illumination intensity vs. open-circuit voltage of solar cells, Solar Energy 76 (1-3) (2004) 263-267.

[43] R.A. Sinton, A. Cuevas, in: Proceedings of the 16th European Photovoltaic Solar Energy Conference, Glasgow, UK, 2000, pp. 1152-1155.

[44] A. Mette, New concepts for front side metallization of industrial silicon solar cells, Thesis, Albert-Ludwigs-Universität Freiburg im Breisgau, FhG ISE, Freiburg, 2007.

[45] M.A. Kroon, R.A.C.M.M. van Swaaij, Spatial effects on ideality factor of amorphous silicon pin diodes, Journal of Applied Physics 90 (2) (2001) 994-1000.

[46] H.G. Wagemann, H. Estrich, Grundlagen der Photovoltaischen Energiewandlung, Teubner, Stuttgart, Germany, 1994. 